\begin{tabular}{|l|}
\hline 008 - 009 \\
Noticias \\
y comentarios \\
PH49 - Julio 2004 \\
\hline
\end{tabular}

PH49 - Julio 2004

\title{
Las Ciudades Americanas Patrimonio de la Humanidad reflexionan sobre la idea de ciudad
}

En la cumbre del Milenio realizada en el año 2000, los 189 países signatarios de Naciones Unidas acordaron una serie de estrategias conocidas como Objetivos de Desarrollo del Milenio (ODM), para reducir a la mitad la proporción de la población que vive con menos de un dólar diario, para el 2015.

En este marco y como estrategia de acompañamiento de los paises para mitigar la pobreza y cumplir con los objetivos propuestos, surgió la Red de Hermandad de Ciudades Patrimonio de la Humanidad. Su objetivo primordial es crear las bases técnicas y científicas para la gestión integral de una red de las ciudades que comparten la designación de la UNESCO como Patrimonio de la Humanidad y que en la actualidad está conformada por 37 ciudades de 16 países de América.

Cuando surgió la idea de crear la Red de Hermandad de Ciudades Patrimonio de la Humanidad se pensó en una herramienta que articulara integralmente los diversos aspectos. Un instrumento que propiciara el intercambio de experiencias y que se constituyera en el espacio propicio para la reflexión de las ciudades. No sólo respecto a su pasado patrimonial, sino al presente; a la idea de ciudad que se pueda construir y especialmente que combine el aprovechamiento adecuado del patrimonio con los usos funcionales que de éste se puedan derivar, desde una perspectiva sostenible.

En la medida en que se han ido consolidando los objetivos de la Red, paralelamente se adelanta desde
Cartagena de Indias, su ciudad sede, la creación de un Observatorio de Ciudades, orientado a reforzar los vínculos y las relaciones de las ciudades y a la construcción de una estructura de indicadores que permitan permanentemente monitorear el progreso hacia los objetivos anteriormente señalados.

Siguiendo estas premisas de intercambio de experiencias, entre el 10 y el 14 de febrero de 2003, se llevó a cabo en Cartagena de Indias el Curso Regional para Editores de Patrimonio de Iberoamérica y el Caribe, con el objetivo de establecer las bases para el Portal de la Red.

Por otra parte, la Red de Ciudades Americanas Patrimonio de la Humanidad ha logrado acercamientos con diferentes ciudades europeas con las que se ha planteado futuros hermanamientos. Adicionalmente, la Red valora la amplia experiencia que otros países de Europa y Asia poseen para conservar integralmente su patrimonio, y es receptiva a las estrategias de cooperación técnica, que le permitan avanzar hacia sus derroteros de forma mancomunada.

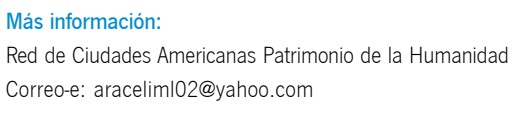

Araceli Moralez López

Coordinadora de la Red de Ciudades

Americanas Patrimonio de la Humanidad

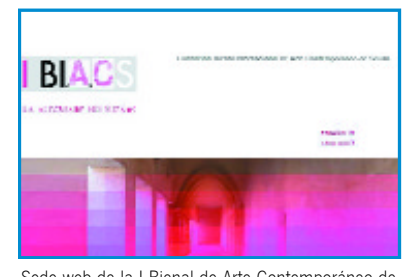

Sede web de la I Bienal de Arte Contemporáneo de Sevilla (BIACS)

\section{El III Encuentro sobre Economía de la Cultura repasa la situación actual del coleccionismo y del mercado del arte}

El III Encuentro sobre Economía de la Cultura, organizado por la asociación OIKOS, que tuvo lugar en las Reales Atarazanas de Sevilla, los dias 25 y 26 de marzo de 2004 tuvo como epígrafes el coleccionismo, el mercado del arte y las repercusiones económicas del mercado del arte y del coleccionismo.

La primera intervención corrió a cargo de Fernando Checa Cremades, quien desde su experiencia como catedrático de Arte de la Universidad Complutense y antiguo director del Museo del Prado, expuso los principios y constantes que han definido la historia del coleccionismo en España. El coleccionismo público: el Sistema Español de Museos fue el título desde el que María del Mar Villafranca, en calidad de Directora General de Instituciones del Patrimonio Histórico, defendió la iniciativa y eficacia de la Administración para el coleccionismo público, en cualquiera de sus modalidades (donación, cesión o adquisición), para definir y engrosar fondos de colec- ciones como la del Museo Picasso de Málaga. En el análisis realizado por el director de la Fundación Rodríguez Acosta, José María Luna Aguilar, las estadísticas y previsiones de futuro legitiman al Museo Picasso no sólo como activador cultural, sino también de la economía de la ciudad de Málaga. La política de adquisición de fondos del Centro Andaluz de Arte Contemporáneo, expuesta por su director, José Lebrero Stals, fue otro ejemplo del coleccionismo público en Andalucía.

Dentro de las sesiones relativas al mercado del arte, la apertura corrió a cargo de la Directora Gerente de la Fundación Bienal de Arte Contemporáneo de Sevilla (BIACS), Juana de Aizpuru, quien centró su intervención en las ferias de ate contemporáneo, en la creación de ARCO (de la que fue fundadora y directora), en su experiencia como galerista y en su nuevo proyecto, la BIACS (ver información adjunta), como modelo de gestión con co- 


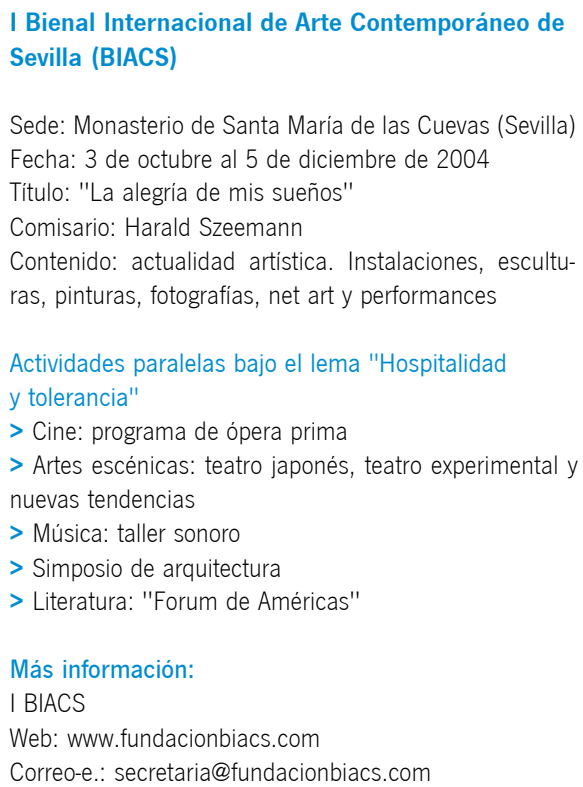

I Bienal Internacional de Arte Contemporáneo de Sevilla (BIACS)

Sede: Monasterio de Santa Maria de las Cuevas (Sevilla) Fecha: 3 de octubre al 5 de diciembre de 2004 Título: "La alegría de mis sueños"

Comisario: Harald Szeemann

Contenido: actualidad artística. Instalaciones, esculturas, pinturas, fotografias, net art y performances

Actividades paralelas bajo el lema "Hospitalidad y tolerancia"

$>$ Cine: programa de ópera prima

$>$ Artes escénicas: teatro japonés, teatro experimental y

nuevas tendencias

$>$ Música: taller sonoro

$>$ Simposio de arquitectura

> Literatura: "Forum de Américas"

Más información:

I BIACS

Web: www.fundacionbiacs.com

Correo-e.: secretaria@fundacionbiacs.com

laboraciones de instituciones públicas y privadas que apuesta por el arte contemporáneo en Sevilla.

Las repercusiones económicas del mercado del arte y del coleccionismo, la tercera parte de este encuentro, contó con la reflexión desde el ámbito de la Teoría Económica sobre el mercado del arte y la economía de la cultura, a cargo de Luis Palma Martos, miembro-fundador de la asociación OIKOS. La importancia económica del mercado del arte y el coleccionismo fue analizada por José Guirao Cabrera, director de la Casa Encendida y profesional de la política cultural en España y de bienes culturales en Andalucía, que realizó un análisis de la política cultural en la segunda mitad del siglo XX en España, las instituciones, el público, los creadores, etc.

Aurora Arjones Fernández

Elena Gómez Jiménez

Centro de Documentación del IAPH
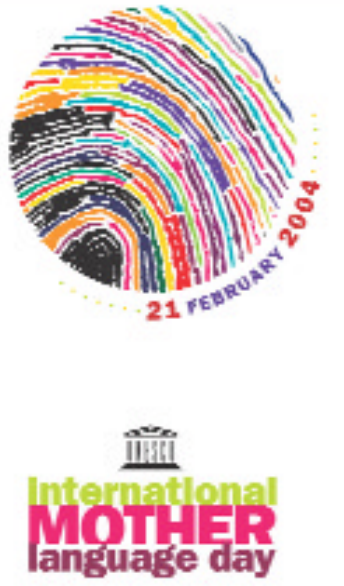

"Si el guaraní se extingue, ¿quién rezará para que no se extinga el mundo?"

(proverbio paraguayo)

\section{Un patrimonio que salvar: 3.000 lenguas en peligro}

Las lenguas son seguramente la más alta creación del ingenio humano, y cada lengua es un testimonio único de la facultad lingüística del ser humano. Las lenguas no sólo son instrumentos sumamente propicios a la comunicación, sino que reflejan también una determinada percepción del mundo: son el vehículo de sistemas de valores y expresiones culturales, y constituyen un factor determinante de la identidad de grupos e individuos. Las lenguas representan una parte esencial del patrimonio vivo de la humanidad.

El pasado 21 de febrero, el Director General de la UNESCO, Koichiro Matsuura, con motivo del Día Internacional de la Lengua Materna lanzaba un mensaje de alerta:

"Las lenguas son un auténtico espejo que refleja la diversidad cultural de la humanidad (...) Me complace que la Convención para la Salvaguardia del Patrimonio Cultural Inmaterial, que la Conferencia General aprobó hace algunos meses, se refiera explícitamente a las lenguas como vectores de dicho patrimonio. Albergo la esperanza de que esta Convención contribuya, a su modo, a preservar la diversidad lingüística, tarea que ya es urgente, visto el ritmo de extinción de las lenguas (dos al mes, en promedio). En particular, pienso en los pueblos autóctonos, para quienes la defensa de la lengua materna sigue siendo una reivindicación capital, con miras a lograr el respeto de su identidad y la salvaguarda de su patrimonio. De modo que la enseñanza de las lenguas, y especialmente del idioma materno, ha llegado a ser más importante que nunca, en un mundo que debe ser capaz de comunicar en una escala mundial, pero que también ha de poder preservarle a cada persona la posibilidad de hablar su propia lengua, como forma prioritaria de expresión, a lo largo de toda su vida" (texto completo en www.unesco.org/education/IMLD2004/).

En esta línea, el Día Internacional de la Lengua Materna, que se celebra anualmente, tiene por objetivo el reconocimiento de todas las lenguas maternas del mundo, particularmente aquéllas minoritarias, así como el fomento de la diversidad lingüistica y la educacion multilingüe y la promoción de la toma de conciencia respecto a las tradiciones lingüisticas y culturales con base en la comprensión, la tolerancia y el diálogo.

Datos para la reflexión

> Más del $50 \%$ de las 6.000 lenguas del mundo corren peligro de desaparecer

> El 96\% de las 6.000 lenguas que hay en el mundo son habladas por el $4 \%$ de la población mundial

> El 90\% de las lenguas del mundo no están representadas en Internet

> Una lengua por término medio desaparece cada dos semanas

> El 80 \% de las lenguas africanas carecen de transcripción escrita

$>$ En tan sólo 8 paises se concentran la mitad de todas las lenguas del mundo: Papua-Nueva Guinea (832), Indonesia (731), Nigeria (515), India (400), México (295), Camerún (286), Australia (268) y Brasil (234)

Más información:

UNESCO

Día Internacional de la Lengua Materna

Web: www.unesco.org/education/IMLD2004/ 